Results Among children of African American mothers, 87/329 (26.4\%) ever had $\mathrm{AD}$ while 19/157 (12\%) children of White mothers ever had $\mathrm{AD}$. Overall, cord blood $25(\mathrm{OH}) \mathrm{D}$ levels were lower in children who ever had $\mathrm{AD}$ (geometric means=GM 30.6 vs $35.6 \mathrm{nmol} / \mathrm{l}$, Wilcoxon Rank Sum=WRS $\mathrm{p}=0.02)$; but the difference was driven by White children (GM 39.7 vs $50.9 \mathrm{nmol} / \mathrm{l}$, WRS $\mathrm{p}=0.036$ ) and not African American children (GM 29.4 vs $29.6 \mathrm{nmol} / \mathrm{l}$, WRS $\mathrm{p}=0.81$ ). The association was also modified by season of birth. Lower $25(\mathrm{OH}) \mathrm{D}$ levels were found in children with $\mathrm{AD}$ born during summer (GM 35.8 vs 45.2 , WRS $\mathrm{p}=0.02$ ), fall (GM 28.1 vs 33.8 , WRS $p=0.036$ ) and winter (GM 30.0 vs 33.7, WRS $\mathrm{p}=0.15)$, but not spring (GM 30.8 vs 31.4 , WRS $p=0.90$ ).

Conclusion Cord blood vitamin $\mathrm{D}$ is associated with $\mathrm{AD}$ at 2 years of age in White but not African American children. The association is also influenced by season of birth.

\section{P2-320 ASTHMA TRENDS IN BRAZILIAN CHILDREN AND ADOLESCENTS: RESULTS FROM THE BRAZILIAN NATIONAL SURVEY (PNAD/IBGE) 1998-2008}

doi:10.1136/jech.2011.142976k.53

F C Wehrmeister,* A M Cascaes, J Martínez-Mesa, A J D Barros, A M B Menezes. Federal University of Pelotas, Pelotas, Rio Grande do Sul, Brazil

Introduction Asthma has a great impact on health services. It affects all ages and it is more prevalent in childhood and adolescence. In South America, including Brazil, there are inconsistencies about the disease trends.

Objective To determine asthma trends from 1998 to 2008, in individuals aged $0-19$ years old in Brazil.

Methods We analysed data of asthma prevalence from the Brazilian National Survey - Pesquisa Nacional por Amostragem de Domicílios (PNAD/IBGE) - of 1998, 2003 and 2008. The analysis was adjusted for the sampling design and included 141, 402; 144, 443; and 134, 032 individuals in 1998, 2003 and 2008 respectively. Prevalence was also estimated by Brazilian macro-regions.

Results The prevalence of asthma among children was $7.71 \%$ in $1998,8.11 \%$ in 2003 and $8.48 \%$ in 2008, with an annual increment of $1 \%$. In the Midwest macro-region there was an annual decline in asthma prevalence in order of $1.09 \%$. In the other macro-regions the prevalence has increased from $0.84 \%$ (South) to $1.52 \%$ (Southeast). Among the group aged 10-19 years the prevalence in 1998 was $4.4 \%$, in 2003 was $4.97 \%$ while in 2008 it was $5.48 \%$. The increase was $2.45 \%$ per year. In the North there was an annual decrease of $0.52 \%$. Other macro-regions showed an increase between $0.88 \%$ (Midwest) and $4.12 \%$ (Northeast).

Conclusions Although asthma is decreasing in developed countries, in Brazil the asthma prevalence in children and adolescents seems to have increased in the period between 1998 and 2008.

\section{P2-321 THE RELATIONSHIP BETWEEN BMI AND WHEEZING IN THE INTERNATIONAL STUDY OF ASTHMA AND ALLERGIES IN CHILDHOOD PHASE 2}

doi:10.1136/jech.2011.142976k.54

${ }^{1} \mathrm{G}$ Weinmayr, ${ }^{1,2} \mathrm{~F}$ Forastiere, ${ }^{1} \mathrm{~A}$ Kleiner, ${ }^{1} \mathrm{G}$ Büchele, ${ }^{1,3} \mathrm{~K}$ Wickens, ${ }^{1,4} \mathrm{D}$ Strachan, ${ }^{1} \mathrm{G}$ Nagel. ${ }^{1}$ Institute of Epidemiology and Medical Biometry, Ulm University, Ulm, Germany; ${ }^{2}$ Dipartimento di Epidemiologia, ASL Roma E, Rome, Italy; ${ }^{3}$ Wellington Asthma Research Group, University of Otago, Wellington, New Zealand; ${ }^{4}$ Division of Population Health Sciences and Education St George's, University of London, London, UK

Introduction An inflammatory link and common genetic factors have been discussed regarding the relation between BMI and asthma. We investigated the relation between obesity and asthma symptoms, and effect modification by atopy and parental allergic disease in Phase 2 of the International Study of Asthma and Allergies in Childhood.

Methods In a population-based cross-sectional study, 10600 children aged 8-12 from 22 centres worldwide were studied with standardised parental questionnaires. Height and weight were measured and age- and sex-specific international BMI cut-off-points were used to define obese children. Atopy was assessed with skin prick testing. Adjusted ORs for each centre were combined with meta-analysis random effects models.

Results Obesity was associated with wheeze in the past year in boys (adjusted OR 1.93 (95\% CI 1.46 to 2.57) and girls 1.51 (1.02 to 2.24). In boys and girls, the effect was the same among atopic and non-atopic children. In boys, the OR was increased in children with reported parental allergic disease compared to those without (2.84 (1.93 to 4.18) and 1.26 (0.8 to 1.98), respectively). Adjustment for parental allergy did not change markedly the association between obesity and wheeze, neither in boys (change from 1.95 to 2.02) nor in girls (1.51 to 1.47).

Conclusions Effect modification but no confounding by parental allergy could indicate that parental allergy does not stand for a common preceding cause of BMI and wheeze (eg, a common genetic pathway), but rather suggests that the influence of BMI may depend on the genetic/family background and also differ between boys and girls.

\section{P2-322 LOW PREVALENCE OF HYPERTENSION IN YEMENITE TYPE 2 DIABETIC PATIENTS}

doi:10.1136/jech.2011.142976k.55

${ }^{1} \mathrm{M}$ B Magnazi, ${ }^{2} \mathrm{~S}$ Weitzman, ${ }^{* 1} \mathrm{~N}$ Reshef, ${ }^{1} \mathrm{~T}$ Zornitzki, ${ }^{1} \mathrm{H}$ Knobler. ${ }^{1}$ Kaplan Medical Center, Rechovot, Israel; ${ }^{2}$ Ben Gurion University of the Negev, Beersheva, Israel

Introduction Previous data suggest that the prevalence of hypertension (HTN) in Yemenite Jews is lower than in the general Israeli population. The aim of the present study was to compare the prevalence of HTN between type 2 diabetic patients of Yemenite $(\mathrm{Y})$ and non-Yemenite (NY) origin.

Methods Cross-sectional study in a Diabetes Clinic. Clinical and lifestyle information was collected including a food frequency questionnaire.

Results Sixty three Y and 120 NY diabetic patients were included in the study. The age and sex distributions were similar in the two groups. Patients in the Y group had lower mean weight and waist circumference $(72.3 \mathrm{~kg}$ vs $85.0 \mathrm{~kg}$ and $95 \mathrm{~cm}$ vs $105 \mathrm{~cm}$, respectively, $\mathrm{p}<0.001)$ and their mean HbA1c level was higher $(7.7 \%$ vs $7.2 \%$, $\mathrm{p}=0.015)$. The prevalence of HTN was significantly lower in the $Y$ compared to the NY group ( $63 \%$ vs $83 \%, p=0.003$ ). Patients in the $Y$ group consumed less antihypertensive medications than those in the NY group (1.6 vs 2.5, $\mathrm{p}=0.002$ ), however blood pressure levels were similar in both groups. In a multivariate logistic regression analysis, NY origin was independently associated with a higher prevalence of HTN (OR 3.0, 95\% CI 1.5 to 6.3, $\mathrm{p}=0.0025$ ). There were no significant differences between the two groups in physical activity, total calories consumed and the DASH score.

Conclusion In this study the prevalence of hypertension in Yemenite was significant lower compared to non-Yemenite diabetic patients. Since no differences were found in lifestyle characteristics it is likely that other mechanisms are involved.

\section{P2-323 WITHDRAWN}

